\title{
Research on the Inheritance and Development of Chinese Traditional Martial Arts
}

\author{
Chen Xianming \\ Wuhan Railway Vocational College Of Technology, Wuhan China
}

\begin{abstract}
Keywords: Traditional Martial Arts; Inheritance; Development
Abstract. Chinese traditional martial art is an important symbol in brilliant traditional culture in China with a long history. Because of the impact of foreign culture and non-ideal inheritance and protection, many of Chinese traditional martial arts are gradually lost, only a few can be handed down. Whether from the cultural protection point of view or from the economic value point of view, it's necessary to research on inheritance and development of traditional martial arts. The article starts from the modern value of traditional martial arts, analyze the development status and the restrictive factors of traditional martial arts and then come up with strategies about inheritance and development, offering theoretical reference for promoting good heritage of traditional martial arts.
\end{abstract}

\section{Introduction}

Traditional martial art is an outstanding national traditional sport in China, it has thousands of years of development history and it plays an important role in enhancing physical fitness and self-cultivation. With the development of economic globalization, heritage and influence between cultures has been more and more widely, traditional martial art was greatly impacted. Under such a background, it's urgent to carry out the relevant protection and development work timely. This is a work that needs to focus on time and make full use of every minute. That starting from modem value and issues of traditional martial arts to discuss is more beneficial to the process of traditional martial arts' inheritance and development. Achieve good protection of traditional culture and let it show the due time value and the historical role.

\section{The concept of traditional martial arts}

Traditional martial art is clearly characterized by the "traditional" word. Tradition means that abiding by ideology, cultural contents, customs and so on, which are handed down by the predecessors. It has temporal continuity and spatial scalability. It is a summary and continuity of history. In fact, tradition is more than a summary and a link to the past, it is the influence and guidance to the descendant. For the traditional martial arts, there is not a very definite concept, different scholars have different views. But in general, traditional martial art is a form of physical activity, it is based on the background of farming civilization, rooted in the traditional culture of our country, absorbs the essence of philosophy, takes routine, Sanda and other skills as the form of expression in order to improve the moral cultivation and combat ability of the practitioner, it is a sports skill which can build fitness as well as have a practical protective effect. From the time line of view, generally considered that traditional martial art is prior to the $1950 \mathrm{~s}$, it has the spread ability and a complete routine system. ${ }^{[1]}$

\section{The modern value of traditional martial arts}

Traditional martial art is a valuable asset of Chinese culture, after thousands of years of development, it still keeps its footing, and inherits all the way, which is because its own value is still available in modern times.

It is a powerful weapon to carry forward the national culture. Traditional martial art is one of the contents of our national culture, it has the basic characteristics of national culture, it has a certain penetration in the ancient Chinese philosophy and medicine. From the style, it also related to the 
aesthetics. It is a typical representative of our national culture. Cultural concept such as false or true complement, dynamic and static complement, unity of man and nature can be traced from the traditional martial arts moves. With the improvement of living standard, people began to pursue the spirit of enjoyment on the basis of material wealth. Therefore, competitive contents between countries began to expand into the cultural field. As an old country with thousands of years of splendid culture, China have the advantage in the competition while we also need to learn the essence and help it heritage and carry forward better. For martial arts, nowadays, there is no lack of martial arts enthusiasts in other countries, some foreigners are more crazy about the martial arts crazy than countrymen. In this situation, more should be done for traditional martial arts, so that it can be handed down better, becoming a characteristic cultural symbol of our country and spreading its charm to every place in the world. Thus, the national self-confidence and pride can be greatly improved. It makes for cohering national emotion, carrying forward the traditional culture.

It has a larger market economic value. When it comes to Chinese martial arts, many people won't feel strange, it can be seen in many movies or TV shows, even Kung Fu films which take martial arts as the main body occupy a certain position in the market wherever in China or on abroad. For instance, the Shaolin Temple in which Jet Li starred is not only popular in China, but also caused a sensation overseas in the 1980s. Hollywood filmed a movie called Kung Fu Panda in 2008. In this movie, Chinese FuHokSeungYing, Praying Mantis, Snake boxing and Monkey boxing were able to show, it provides a better platform for propagandizing our martial arts. In 2013, the movie The Grandmaster displayed and introduced Wing Chun to the world by the form of movies. What's more, movies with the subject of martial arts all have decent box office, this is a direct embodiment of traditional martial arts market economy value. Chinese martial arts began to get support from the policy since 1995, martial arts career has developed rapidly. martial arts halls and gyms began to rise, sports and performance activities related to martial arts began to be the rage as well. Martial arts-related tourism industry began to enter the hot spots of tourism in the context of martial arts culture. It is such an all - round development promotes economic development, thus demonstrating the economic value of martial arts $t$ with the leading effect of related industry. Take the World Traditional Martial Arts Festival held in Hubei in 2008 as an example, by holding this martial arts festival, Wudang Mountain's tourism has been vigorous development. Only the signing with travel agencies and funds have reached 2.4 billion, including money from foreign investors [2].

It helps set more accurate standards and cultivate noble personality quality. Martial artists usually learn ethics at first, it is a principle that has never changed, one must learn how to behave, only noble virtues can make martial arts as a protective skill and will not let martial arts become a tool of violence. Chinese traditional martial arts take righteousness as core, attaching importance to respecting the old, faith of others and the maintenance of peace and justice. From the basic moral point of view of such martial arts, practicing Kung Fu can not only build fitness, but also be influenced by the essence of martial arts, growing into a man of indomitable spirit. The cultivation of noble virtues plays a decent role in developing and building correct values, it can help people improve their own quality continuously and grow into a person with strong moral character and noble moral sentiment.

It helps build fitness, improve the health of nations. When it comes to national constitutional, many people will show the phenomenon of poor health. Because investigations and reports on the poor constitution of the people, especially the middle and primary school students are still common in recent years. The practice of martial arts can achieve the goal of physical fitness be beneficial to improve the health of nations by moves. At present, many schools add martial arts to physical education, some even replace morning exercises with martial arts. This also lets martial arts play role in physical fitness.

\section{The development situation of traditional martial arts and constraints}

The development situation of traditional martial arts. (1) the domestic development situation. As a typical representative, traditional martial art was flourishing In the Ming and Qing dynasties. 
Martial art masters arose, the development of related martial arts routine system was mature and it formed distinguishing features. But after the Opium War began, the development of Chinese martial arts has been limited, fewer people learned martial arts, some traditional martial arts were lost because nobody studied them, so that martial arts are vanishing. In just 50 years, the number of species is reduced by nearly 2000, only 129 handed down, and more than two-thirds that nobody can practice or demonstrate with items. Nowadays, the items we see are widely circulated, such as Wing Chun, Shaolin martial arts and shadowbox. Others do not spread wildly. Martial arts that are not able to be listed in the national nonmaterial cultural heritage list begin to be at the brink of disappearance. Some have disappeared already [3].

Our country has enrolled martial arts in physical education. But from the implementation point of view, there are few school that set up martial arts class indeed. And the hardware and software equipment, teaching facilities are scarce. Some martial art teachers with halfway understanding on the essence of martial arts cannot arouse students' learning interest, it will check the spread of martial arts among students, leading to the phenomenon that mostly the old practice martial arts. It is easy to be lack of successors. The Inheritance of martial arts needs a certain cultural carrier as well. There are not many martial arts competitions held in China have relation to traditional martial arts in recent years, even there are some, traditional martial arts are influenced in heritage because competitors attach too much importance in performance and gold medals.

(2) Foreign development situation. Chinese traditional martial arts got the extensive concern of international community by audiovisual works and performances since the 1980s. In 1990, International Wushu Federation was established. After 20 years of development, members of International Wushu Federation have risen to nearly 150, transmitting athletic martial arts all over the world. However, traditional martial arts need a certain background. A lot of foreigners are not familiar with Chinese martial arts, they even think that martial arts are competitive routine, and know little about the culture behind. With the promotion of variety shows such as WU LIN FENG, some China-Thailand, Sino-American martial arts competitions begin to develop on the commercial background, which makes many foreigners believe that Sanda and actual combat works, and the essence of traditional martial starts to be forgotten [4].

The restrictive factors of traditional martial arts development. (1) External factors.The development of anything requires some support from external environment, if, external factors are not conducive to the development of things, the growth and development of things is bound to be constrained. When we talked about the essence of traditional martial arts, the art of attack and defense is one of its main features, in the feudal era, martial art was used widely in war and people's self-defense. With the production of weapons and social stability and harmonious development, martial arts application environment has also changed, lost the original survival of the soil. Furthermore, under the background of the integration of global sports events, the traditional martial arts have been affected. At present, the Olympic Games has become the world's largest sports event and the supreme halls of competitive sports, while not included in the Olympic Games, martial art is subject to impact. The daily sports habits of primary and secondary students show that the traditional sports like football, basketball, track and field and other sports are still firmly in their position, in addition, some sports introduced from foreign countries such as yoga, cheerleading, taekwondo, hip-hop are sought after by people, but our own traditional martial art has been left out, which makes China's martial arts culture be faced with the problem of being assimilated or even being forgotten. In recent years, although with the support of the government, a number of martial arts courses and games have been to carry out so that people gradually increase the understanding of traditional martial arts. However, martial arts competitions are too seriously in competitive and commercial, competitive martial arts are too focused on the corresponding routines and ornamental, artistic, out of the right development track of martial arts, cultural connotation and the essence of martial arts in the process of development gradually lost and disappear in people's field of vision [5].

(2) Internal factor.China's traditional martial art was developing in agricultural civilization, has typical characteristics of small peasant consciousness, with a certain degree of conservative, the inheritance of martial arts has certain rules, for someone who is not the disciple of the school, martial 
arts will not be taught. As to the teaching methods of martial arts, most people teach through words and action, the teaching is lack of corresponding text information, which we called" The top-secret book of Kungfu" in martial arts film. As time goes on, in the absence of a written record, the traditional martial arts heritage is also becoming more and more difficult. For practice of martial arts, practitioner needs comprehension, so he or she can understand the philosophy behind martial arts, otherwise he or she cannot achieve a perfect master of martial arts. Martial arts practice is not the work of a single day, it needs several years or even decades to master martial arts, and with increase of social experience, people will have different understanding of martial arts. Due to the accelerated pace of modern life, few people will have the patience to accept such a long-time practice, so the inheritance of martial arts is affected by human' s subjectivity. With the development of film and television culture, we can find vague impression of martial arts in many TV and film works. Especially in some martial arts films, the impression like" treading on snow without footprints", "walk on water"," attacking acupuncture point" emerge in endlessly, through artistic means and film and television special effects make traditional martial arts left a mysterious image, giving people visual enjoyment and impact, at the same time, affecting people's impression of traditional martial arts. Once people immersed in the full of beauty and impact of the film and television martial arts, they would have psychological gap when come into contact with the true traditional martial arts, so that people are not interested in traditional martial arts. There are various types of martial arts in our country, various faction has their own characteristics. Each kind of martial arts has its own routines system and the corresponding equipment, for example, only classified tai chi according to the founder's last name as Chen, Zhou, king, and so on. Martial arts used a variety of weapons, even for the same martial arts, in different occasions or in the face of different opponents, there will be differences in the use of equipment. This is not only a beautiful manifestation of traditional Chinese martial arts flourishing, but also increases the difficulty of learning martial arts, making the inheritance of martial arts encounter difficulties.

\section{The traditional martial arts heritage methods}

Excellent traditional culture needs to continue its value through inheritance, martial art is no exception. The inheritance of traditional martial arts not only enriches the form of sports activities, but also makes the excellent traditional culture of our country get a good development. Traditional martial arts heritage, mainly through four ways: the blood reason, mentoring relationship, the region reason and the profession reason. In fact, the heritage way of the blood reason is the form of family heritage, this form is not unfamiliar to a lot of people, the owner of martial arts will teach people whom have blood relationship with the owner, this approach is quite common in the traditional teaching of martial arts. Mentoring is also the traditional form of traditional martial arts heritage, which is a certain degree of imitation of the family relationship model. Through the recruitment of disciples, the completion of the corresponding recruit ceremony to determine the identity of martial arts practitioners and the right to learn martial arts. This approach is a form of obligation, does not charge any fees, is conducive to the experience accumulation of martial arts of a school, but not conducive to the exchange of martial arts, does not have enough living space in today's society. The region reason refers to the fact that in a particular geographical environment, people in the same environment, sharing the same cultural background and environment, are easy to have same psychology and behavior. When they have same feeling to a kind of martial arts, they will exchange and teach each other, which forms a geographical inheritance. The profession reason is reality that people have the same occupation or hobbies, resulting in the exchange of martial arts for each other and spreading in an activity. This approach is the most important way of traditional martial arts transmission in current environment, to avoid the thought of inheritance according to blood leading to the demise of martial arts. 


\section{Strategies for the inheritance and development of traditional martial arts}

Increase the government's efforts in support, promote the strategic position of traditional martial arts culture.Traditional martial art is a kind of culture, if we want to achieve good development of martial arts, we need to put it in the position of cultural strategy to inherit and develop. The government's support is quite important in this issue. Economic martial arts and related martial arts business grow up in recent years, we realize that their development benefited from the government's support and related funding. To change the difficult situation of traditional martial arts, the government should come out, provide support from policy and funding, increase the publicity and promotion efforts, promote the strategic position of traditional martial arts culture constantly. As a kind of national culture, martial art belongs to sports but is not only sport, it needs to follow the rules of martial arts and cultural characteristics to carry on the inheritance and development.

From the perspective of government policy support, we can start with aspects like establishment of relevant place of martial arts and security, at the same time we can also organize some related games and activities that are tailor-made for traditional martial arts, and improve the corresponding rules of the game, stimulate the enthusiasm of the participants through the appropriate incentive mechanism. From view of financial support, we should increase the government's capital investment, for traditional martial arts-related clubs and training teams we can give tax concessions, and even issued a special martial arts lottery, we can give students who study traditional martial arts in colleges subsidies and concessions of tuition and fees.

In the context of the market, the government's support should be based on the background of social needs, collaborate with companies, spread knowledge of traditional martial arts by film and television, books, online games and other ways. For enterprises, which distinctively integrate traditional culture into the product give some reward, so we can make significant progress in promoting the strategic position of martial arts culture [6].

Increase publicity efforts, expand the effective coverage of traditional martial arts. Traditional martial arts originated from the working people's long-term productive labor and life, is the crystallization of wisdom, and has a good development result from inheritance in many years. Because of the impact of foreign culture and weakness of inheritance, the traditional martial arts gradually fade out of sight, which is bad to heritage and development. For this reason, it is necessary to increase propaganda of traditional culture. Not only propagandize in traditional ways such as television, newspapers, radio, but also make good use of new media tools, conduct propaganda by emerging micro-blog, WeChat and QQ, to carry out cultural penetration in ways close to people's reading habits. Organize people to shoot related public service advertising or micro film, with the cultural spirit traditional behind martial arts as the main idea, promote the integrative development of publicity. Besides traditional propaganda of traditional martial arts in these ways, the effective coverage of the propaganda also should be fully considered. In rural areas, carry out publicity column according to the level of the local economy and conditions, even through the actual martial arts performances in villages, to achieve effective coverage of propaganda, thereby improving people's recognition of martial arts.

Set up martial arts institute, carry out protection and inheritance work. Traditional martial art is an important cultural heritage of China, and some martial arts types because of the lack of attention, on the brink of extinction. We can systematically carry out the protection and transmission of martial arts by setting up martial arts institute. By carrying out the relevant rescue and finishing work, sort and file the data of traditional martial arts, to promote the efficiency of the work of protection. Furthermore, the establishment of institute is conducive to the development of related research topics. By the research of the subject, we can promote the innovation of traditional martial arts protection way, and make its inheritance be propelled by the times, not be far away from the development background of the times. Today, with the development of science and technology the working mode of the institute can also be improved, the use of information technology, digital processing model can effectively achieve the preservation of resources, and through the relevant data 
evaluate the development of traditional martial arts, to provide new adjustment and reform direction to protection and inheritance work.

\section{Conclusion}

Traditional martial art is a symbol of the unity of man and nature and the spirit of keeping self improvement. In the development of traditional martial arts, it has been renewed and developed constantly and has become a cultural product with both historical and cultural connotations and characteristics of the times. For the protection and inheritance of traditional martial arts, it is necessary to retain its importance and value of the times, analyze its development status and related constraints, objectively carry on the inheritance and development strategy from multiple aspects, provide help to good development of traditional martial arts, achieve the life and growth in nature and passing from generation to generation of the Chinese outstanding culture.

\section{References}

[1] Liang Shiyun. Research on Inheritance problem of traditional martial arts and Countermeasures[J]. Chinese Wushu Research,2014(02)

[2] Li Xiaomei. Research on Inheritance and Development Problem of Chinese Traditional Martial Arts[J]. Sports Time,2014(04)

[3] Li Guohui. Research on Inheritance of Chinese Traditional Martial Arts[J]. Sport Boutique,2014(05)

[4] Ren Yuanyuan. Research on Inheritance and Development of Chinese Traditional Martial Arts[J]. Sports Time,2014(14) (in Chinese)

[5] Huang Lei. Brief Discussion on Inheritance and Development of Chinese Traditional Martial Arts[J]. Science \& Technology Vision,2013(31) (in Chinese)

[4] Gong Xiaoquan. A Brief Analysis on Inheritance and Development of Traditional Martial Arts[J]. Sports Time,2012(12) (in Chinese) 